\title{
Glucose Metabolism during Leg Exercise in Man
}

\author{
John Wahren, Philip Felig, Gunvor Ahlborg, and Lennart Jorfeldt \\ From the Department of Clinical Physiology of the Karolinska Institute at the \\ Seraphimer Hospital, 11283 Stockholm, Sweden, and the Department of \\ Internal Medicine, Yale University School of Medicine, \\ New Haven, Connecticut 06510
}

A B S T R A C T Arterial concentrations and net substrate exchange across the leg and splanchnic vascular bed were determined for glucose, lactate, pyruvate, and glycerol in healthy postabsorptive subjects at rest and during $40 \mathrm{~min}$ of exercise on a bicycle ergometer at work intensities of 400,800 , and $1200 \mathrm{~kg}-\mathrm{m} / \mathrm{min}$.

Rising arterial glucose levels and small decreases in plasma insulin concentrations were found during heavy exercise. Significant arterial-femoral venous differences for glucose were demonstrated both at rest and during exercise, their magnitude increasing with work intensity as well as duration of the exercise performed. Estimated glucose uptake by the leg increased 7 -fold after $40 \mathrm{~min}$ of light exercise and 10 - to 20 -fold at moderate to heavy exercise. Blood glucose uptake could at this time account for $28-37 \%$ of total substrate oxidation by leg muscle and $75-89 \%$ of the estimated carbohydrate oxidation.

Splanchnic glucose production increased progressively during exercise reaching levels 3 to 5 -fold above resting values at the heavy work loads. Close agreement was observed between estimates of total glucose turnover during exercise based on leg glucose uptake and splanchnic glucose production. Hepatic gluconeogenesis -estimated from splanchnic removal of lactate, pyruvate, glycerol, and glycogenic amino acids-could supply a maximum of $25 \%$ of the resting hepatic glucose production but could account for only $6-11 \%$ of splanchnic glucose production after $40 \mathrm{~min}$ of moderate to heavy exercise.

It is concluded that: (a) blood glucose becomes an increasingly important substrate for muscle oxidation dur-

A preliminary report on part of this work was presented at the Karolinska Institute Symposium on "Muscle Metabolism During Exercise," Stockholm, Sweden, 6 September 1970 (1).

Dr. Felig is a Teaching and Research Scholar of the American College of Physicians.

Received for publication 14 June 1971 and in revised form 29 July 1971. ing prolonged exercise of this type; $(b)$ peripheral glucose utilization increases in exercise despite a reduction in circulating insulin levels ; $(c)$ increased hepatic output of glucose, primarily by means of augmented glycogenolysis, contributes to blood glucose homeostasis in exercise and provides an important source of substrate for exercising muscle.

\section{INTRODUCTION}

The liver is generally recognized as the only significant source of blood glucose after a postabsorptive period of 10-14 hr. The estimated net splanchnic glucose production in postabsorptive man $(0.8-1.4 \mathrm{mmoles} / \mathrm{min})$ is sufficient to cover the glucose oxidation of the brain and to supply fuel for the obligatory glycolytic tissues but leaves little room for glucose oxidation by other tissues (2). Accordingly, both the respiratory quotient and direct measurements of substrate uptake by resting human skeletal muscle have indicated that glucose metabolism is of minor importance ( 3 ) compared with the oxidation of fat in the form of free fatty acids (4). On the other hand, during physical exertion when substrate availability and interrelationships are drastically altered, there is indirect isotopic evidence of an accelerated whole body glucose turnover (5). In contrast, direct estimates of muscle glucose uptake during exercise in man have yielded divergent results; considerable glucose uptake has been reported $(6-8)$, but so has virtual nonutilization of this substrate (9-11). Methodological problems in the determination of small arterio-venous glucose differences may well have contributed to the discordant results. However, some of the differences may also be referrable to variation in the intensity, duration, and type of exercise performed (1). In addition, although increased mobilization of glucose from the liver has been observed during exercise $(12,13)$, previous studies have not attempted to correlate peripheral and splanchnic glucose balance. The present study was therefore undertaken to quantify the importance of blood glucose as a sub- 
TABLE I

Heart Rate, Oxygen Uptake, and Estimated Leg Blood Flow at Rest and after 10 and 40 min of Exercise at Various Work Intensities*

\begin{tabular}{|c|c|c|c|c|c|c|c|c|c|c|c|c|c|c|}
\hline \multirow[b]{4}{*}{ Heart rate, beals/min } & & & \multicolumn{12}{|c|}{ Exercise } \\
\hline & & & \multicolumn{4}{|c|}{$400 \mathrm{~kg}-\mathrm{m} / \mathrm{min}$} & \multicolumn{4}{|c|}{$800 \mathrm{~kg}-\mathrm{m} / \mathrm{min}$} & \multicolumn{4}{|c|}{$1200 \mathrm{~kg}-\mathrm{m} / \mathrm{min}$} \\
\hline & \multicolumn{2}{|c|}{ Rest } & \multicolumn{2}{|c|}{$10 \mathrm{~min}$} & \multicolumn{2}{|c|}{$40 \mathrm{~min}$} & \multicolumn{2}{|c|}{$10 \mathrm{~min}$} & \multicolumn{2}{|c|}{$40 \mathrm{~min}$} & \multicolumn{2}{|c|}{$10 \mathrm{~min}$} & \multicolumn{2}{|c|}{$40 \mathrm{~min}$} \\
\hline & 60 & \pm 3 & 94 & \pm 6 & 109 & \pm 8 & 135 & \pm 8 & 146 & \pm 9 & 140 & \pm 4 & 158 & \pm 3 \\
\hline Oxygen uptake, $\mathrm{ml} / \mathrm{min}$ & 256 & \pm 19 & 943 & \pm 29 & 1010 & \pm 40 & 1691 & \pm 43 & 1811 & \pm 69 & 2279 & \pm 172 & 2532 & \pm 126 \\
\hline Respiratory quotient & 0.77 & \pm 0.01 & 0.79 & \pm 0.02 & 0.80 & \pm 0.02 & 0.85 & \pm 0.01 & 0.82 & \pm 0.01 & 0.87 & \pm 0.02 & 0.8 & $7 \pm 0.03$ \\
\hline A-FV oxygen diff., $m l / l i t e r$ & 61.5 & \pm 6.6 & 145.5 & \pm 5.2 & 149.8 & \pm 5.7 & 157.0 & \pm 6.8 & 165.7 & \pm 5.8 & 148.5 & \pm 3.0 & 156.2 & \pm 7.0 \\
\hline FV oxygen saturation, \% & 59.4 & \pm 6.0 & 24.1 & \pm 1.7 & 20.7 & \pm 3.0 & 19.2 & \pm 3.7 & 13.4 & \pm 1.5 & 19.7 & \pm 1.0 & 15.0 & \pm 1.1 \\
\hline Leg blood flow, liter/min & 0.92 & \pm 0.05 & 3.69 & \pm 0.11 & 4.06 & \pm 0.12 & 7.12 & \pm 0.44 & 7.2 & \pm 0.39 & 10.25 & \pm 0.75 & 10.9 & \pm \pm 0.59 \\
\hline Hematocrit, $\%$ & 41.6 & \pm 0.7 & 44.0 & \pm 0.6 & 44.0 & \pm 0.5 & 45.1 & \pm 1.0 & 44.6 & \pm 0.7 & 43.9 & \pm 1.0 & 43.2 & \pm 0.8 \\
\hline
\end{tabular}

* Data are presented as mean $\pm \mathrm{SE}$.

strate for exercising muscle and to examine the role of hepatic glycogenolytic and gluconeogenic processes in the maintenance of glucose homeostasis during physical exertion. The response to exercise at different intensities and durations has been investigated by simultaneous determinations of net balance of glucose, lactate, and pyruvate across the exercising leg and splanchnic vascular bed in postabsorptive man. In addition, the relation of splanchnic glucose balance to true hepatic glucose output has been estimated by examining arterio-portal venous glucose differences in subjects undergoing elective cholecystectomy. Studies on amino acid metabolism in the exercised subjects are reported separately (14).

\section{METHODS}

Subjects. All subjects were healthy adult male volunteers. Three were students, all the others were employed by the Stockholm fire department. Data for age, height, and weight on individual subjects have been reported pre-

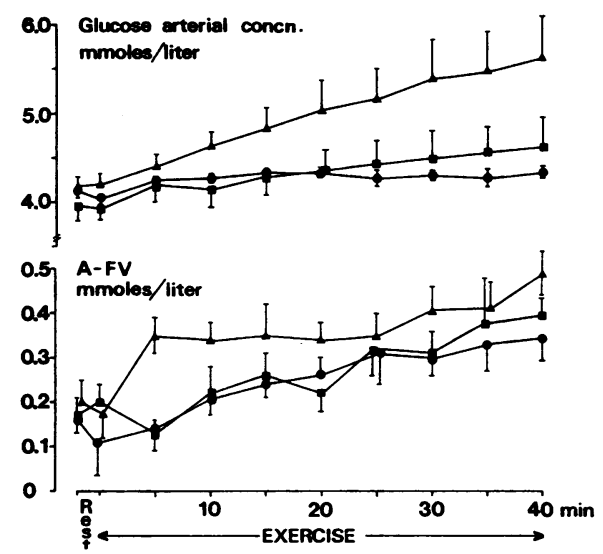

FIGURE 1 Arterial glucose concentrations and arterialfemoral venous (A-FV) glucose differences at rest and during exercise (mean $\pm \mathrm{SE}$ ) at work loads of $400 \mathrm{~kg}-\mathrm{m} / \mathrm{min}$ $(\longrightarrow), 800 \mathrm{~kg}-\mathrm{m} / \mathrm{min}$ ( $\square$ ), and $1200 \mathrm{~kg}-\mathrm{m} / \mathrm{min}$ $(\mathbf{\Delta} \mathbf{\Delta})$. viously (14). Four subjects were studied on more than one occasion, at different work loads. One subject was studied twice at a work load of $1200 \mathrm{~kg}-\mathrm{m} / \mathrm{min}$. None of the subjects participated in training programs or competitive athletics on a regular basis. They were informed of the nature, purpose, and risks involved in the study before giving their voluntary consent.

Procedure. The subjects were studied after an overnight fast in the resting state and during upright exercise for $40 \mathrm{~min}$ on a bicycle ergometer at work loads of 400,800 , or $1200 \mathrm{~kg}-\mathrm{m} / \mathrm{min}(1 \mathrm{~kg}-\mathrm{m} / \mathrm{min}=0.163 \mathrm{w})$. The techniques employed for catheterization of the brachial artery, femoral vein, and hepatic vein, for determination of hepatic blood flow (15-17), and for collection of expired air have been described elsewhere (14). Blood flow to both legs was estimated from pulmonary oxygen uptake and the arterialfemoral venous oxygen difference according to the formulas of Jorfeldt and Wahren (18) as described previously (14). Blood samples were collected simultaneously from the brachial artery and the femoral and hepatic veins at rest and repeatedly at timed intervals during exercise. In two subjects blood samples were also obtained from a catheterized right sided renal vein. Total blood loss during each study was less than $250 \mathrm{ml}$.

Analyses. Glucose was analyzed in whole blood using the glucose oxidase reaction (19). In view of the sometimes minute arterio-venous glucose differences measured in this study, it was considered important to determine that such differences were not due to the presence in arterial or venous blood of nonspecific reducing and oxidizing substances which respectively, compete with the chromogen for hydrogen peroxide or cause nonspecific chromogen oxidation. This was tested in three different ways. Firstly, when small amounts of a glucose standard solution were added to arterial and venous blood $(n=10)$, the measured recoveries did not differ significantly $(97.7 \pm 2.8$ and $97.9 \pm 2.6 \%$ respectively, mean $\pm \mathrm{SD}$ ). Secondly, the effect of nonspecific hydrogen peroxide consumption in the reaction system was tested as described by Hjelm and de Verdier (20) by incubating the blood extract with all reagents of the reaction except glucose oxidase and measuring the color development when known amounts of hydrogen peroxide were added. Arterial and femoral venous blood samples obtained both at rest and during heavy exercise in three subjects were tested in this way. Using the paired $t$ test it was found that arterial and venous samples did not differ in this respect $(t=1.18, n=25)$. However, both types of samples gave 
TABLE II

Arterial Concentrations of Glucose, Lactate, Pyruvate, Glycerol, and Free_Fatty Acids at Rest and during Exercise at Different Work Loads*

\begin{tabular}{|c|c|c|c|c|c|c|c|c|c|c|c|c|}
\hline \multirow{4}{*}{$\begin{array}{c}\begin{array}{c}\text { Work } \\
\text { load }\end{array} \\
k g-m / \min \\
\text { Glucose }\end{array}$} & \multirow{4}{*}{$\mathbf{n}$} & \multirow{2}{*}{\multicolumn{2}{|c|}{ Rest $\ddagger$}} & \multicolumn{9}{|c|}{ Exercise } \\
\hline & & & & \multirow[t]{3}{*}{$5 \mathrm{~min}$} & \multicolumn{2}{|c|}{$10 \mathrm{~min}$} & \multicolumn{2}{|c|}{$20 \mathrm{~min}$} & \multicolumn{2}{|c|}{$30 \mathrm{~min}$} & \multicolumn{2}{|c|}{$40 \mathrm{~min}$} \\
\hline & & \multirow{2}{*}{\multicolumn{10}{|c|}{ mmoles/liter }} & \\
\hline & & & & & & & & & & & & \\
\hline 400 & 10 & 4.15 & \pm 0.06 & $4.25 \pm 0.04$ & 4.26 & \pm 0.05 & 4.33 & \pm 0.05 & 4.30 & \pm 0.06 & 4.34 & \pm 0.06 \\
\hline 800 & 9 & 4.16 & \pm 0.12 & $4.20 \pm 0.19$ & 4.15 & \pm 0.21 & 4.36 & \pm 0.23 & 4.49 & \pm 0.27 & 4.62 & \pm 0.33 \\
\hline 1200 & 6 & 4.19 & \pm 0.11 & $4.40 \pm 0.13$ & 4.63 & \pm 0.16 & 5.04 & \pm 0.32 & 5.39 & \pm 0.41 & 5.63 & \pm 0.44 \\
\hline \multicolumn{13}{|l|}{ Lactate } \\
\hline 400 & 10 & 0.63 & \pm 0.05 & $1.13 \pm 0.16$ & 1.01 & \pm 0.12 & 0.95 & \pm 0.11 & 0.90 & \pm 0.09 & 0.88 & \pm 0.11 \\
\hline 800 & 9 & 0.73 & \pm 0.05 & $2.88 \pm 0.40$ & 2.71 & \pm 0.50 & 2.72 & \pm 0.65 & 2.26 & \pm 0.42 & 2.02 & \pm 0.43 \\
\hline 1200 & 6 & 0.68 & \pm 0.09 & $3.12 \pm 0.65$ & 2.75 & \pm 0.59 & 2.76 & \pm 0.63 & 2.73 & \pm 0.61 & 3.51 & \pm 1.15 \\
\hline \multicolumn{13}{|c|}{ Pyruvate } \\
\hline 400 & 10 & 0.065 & \pm 0.004 & & 0.086 & \pm 0.009 & 0.078 & \pm 0.006 & 0.080 & \pm 0.007 & 0.079 & \pm 0.009 \\
\hline 800 & 9 & 0.075 & \pm 0.004 & & 0.173 & \pm 0.022 & & & & & 0.179 & \pm 0.026 \\
\hline 1200 & 6 & 0.066 & \pm 0.003 & & 0.155 & \pm 0.019 & & & & & 0.154 & \pm 0.023 \\
\hline \multicolumn{13}{|l|}{ Glycerol } \\
\hline 400 & 3 & 0.035 & \pm 0.006 & & 0.126 & \pm 0.029 & 0.141 & \pm 0.037 & & & 0.195 & \pm 0.048 \\
\hline 800 & 3 & 0.081 & \pm 0.016 & & 0.139 & \pm 0.038 & 0.195 & \pm 0.040 & & & 0.277 & \pm 0.039 \\
\hline 1200 & 6 & 0.062 & \pm 0.006 & & 0.188 & \pm 0.018 & 0.290 & \pm 0.023 & & & 0.420 & \pm 0.035 \\
\hline \multicolumn{13}{|c|}{ Free fatty acids } \\
\hline 400 & 8 & 0.553 & \pm 0.038 & & 0.475 & \pm 0.016 & 0.635 & \pm 0.021 & & & 0.707 & \pm 0.063 \\
\hline 800 & 6 & 0.489 & \pm 0.070 & & 0.382 & \pm 0.040 & 0.462 & \pm 0.069 & & & 0.514 & \pm 0.080 \\
\hline 1200 & 6 & 0.614 & \pm 0.095 & & 0.434 & \pm 0.056 & 0.537 & \pm 0.066 & & & 0.653 & $3 \pm 0.014$ \\
\hline
\end{tabular}

* Data presented as mean $\pm \mathrm{SE}$ in millimoles/liter.

$\ddagger$ Data for the resting state represent the mean of $2-4$ observations at 5- to 10 -min intervals in each subject.

a 7-10\% hydrogen peroxide consumption not found with the blank, which is in agreement with previous published data (20). Finally, nonspecific oxidation of the chromogen was tested by adding extracts of the above mentioned arterial and femoral venous samples to a reaction mixture in which the glucose oxidase had been omitted. No measurable color development was found for either type of sample. It is thus concluded that the measured arterial-venous blood glucose differences reported below are not a consequence of nonspecific inteferring substances in either arterial or venous blood.

Lactate (21), pyruvate $(22,23)$, and glycerol (24) were determined in whole blood enzymatically. Free fatty acids in plasma were analyzed by gas chromotography (25). Insulin was measured in plasma by radioimmunoassay with the use of talc to separate bound and free insulin (26).

Blood samples for analysis of oxygen saturation and hemoglobin concentration were drawn into $10-\mathrm{ml}$ siliconized glass syringes. Oxygen saturation was determined spectrophotometrically by a slightly modified form of the method of Drabkin (27). Hemoglobin concentration was analyzed using the cyanmethemoglobin technique (28). Indocyanine green was determined spectrophotometrically at $805 \mathrm{~nm}$. A calibration curve was made for each subject with known dilutions of the dye solutions used. Hematocrit was determined using a microcapillary hematocrit centrifuge and a correction for trapped plasma (29). Expired air was analyzed using the Scholander microtechnique.
For the various chemical analyses, the error of the method expressed as the coefficient of variation for a single determination was as follows: glucose, $1.3 \%$; lactate, $6.8 \%$ (0-1 mmoles/liter) and $3.2 \%$ (1-10 mmoles/liter); pyru-

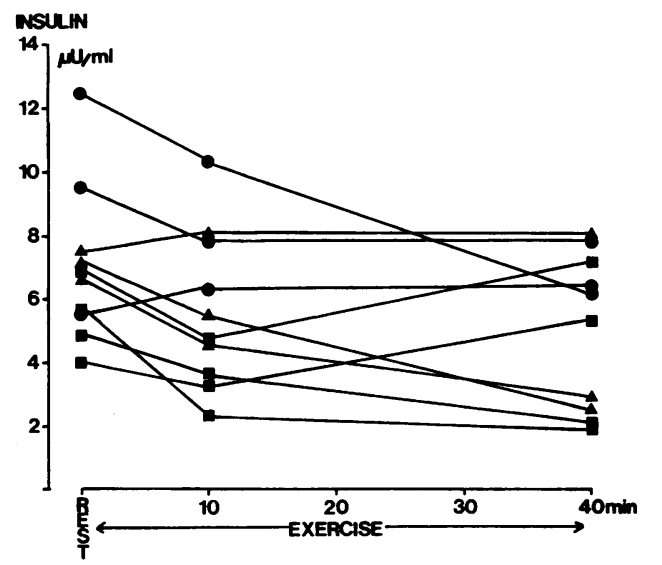

FIgURE 2 Insulin concentration of arterial plasma at rest and during exercise at different work loads. Symbols as in Fig. 1. 


\section{TABLE III}

'Arterial-Femoral Venous Differences $(A-F V)$ for Glucose, Lactate, and Pyruvate at Rest and during Exercise at Different Work Loads*

\begin{tabular}{|c|c|c|c|c|c|c|c|c|c|c|c|c|c|c|}
\hline \multirow[b]{2}{*}{$A-F V$} & \multirow{2}{*}{$\begin{array}{l}\text { Work } \\
\text { load }\end{array}$} & \multirow[b]{2}{*}{$\mathbf{n}$} & \multirow{2}{*}{\multicolumn{2}{|c|}{ Rest $\ddagger$}} & \multicolumn{10}{|c|}{ Exercise } \\
\hline & & & & & \multicolumn{2}{|c|}{$5 \mathrm{~min}$} & \multicolumn{2}{|c|}{$10 \mathrm{~min}$} & \multicolumn{2}{|c|}{$20 \mathrm{~min}$} & \multicolumn{2}{|c|}{$30 \mathrm{~min}$} & \multicolumn{2}{|c|}{$40 \mathrm{~min}$} \\
\hline \multicolumn{15}{|c|}{$k g-m / \min$} \\
\hline \multirow{4}{*}{$\begin{array}{l}\text { Glucose, } \\
\text { mmoles/liter }\end{array}$} & & & & & & & & & & & & & & \\
\hline & 400 & 10 & 0.14 & \pm 0.05 & 0.14 & \pm 0.02 & 0.21 & \pm 0.04 & 0.26 & \pm 0.04 & 0.30 & \pm 0.04 & 0.36 & \pm 0.05 \\
\hline & 800 & 9 & 0.19 & \pm 0.04 & 0.13 & \pm 0.04 & 0.22 & \pm 0.06 & 0.22 & \pm 0.04 & 0.31 & \pm 0.05 & 0.40 & \pm 0.04 \\
\hline & 1200 & 6 & 0.25 & \pm 0.06 & 0.35 & \pm 0.04 & 0.34 & \pm 0.04 & 0.34 & \pm 0.04 & 0.41 & \pm 0.05 & 0.49 & \pm 0.05 \\
\hline \multirow{4}{*}{$\begin{array}{l}\text { Lactate, } \\
\text { mmoles/liter }\end{array}$} & & & & & & & & & & & & & & \\
\hline & 400 & 10 & -0.15 & \pm 0.03 & -0.07 & \pm 0.08 & -0.11 & \pm 0.04 & -0.14 & \pm 0.08 & -0.08 & +0.03 & -0.09 & \pm 0.05 \\
\hline & 800 & 8 & -0.14 & \pm 0.06 & -0.10 & \pm 0.13 & -0.23 & \pm 0.18 & -0.11 & \pm 0.07 & -0.08 & \pm 0.04 & -0.04 & \pm 0.05 \\
\hline & 1200 & 6 & -0.04 & \pm 0.11 & -0.13 & \pm 0.17 & -0.03 & \pm 0.03 & -0.14 & \pm 0.04 & -0.06 & \pm 0.06 & -0.12 & \pm 0.19 \\
\hline \multirow{4}{*}{$\begin{array}{l}\text { Pyruvate, } \\
\text { mmoles/liter }\end{array}$} & & & & & & & & & & & & & & \\
\hline & 400 & 10 & -0.002 & $\pm \mathbf{0 . 0 0 3}$ & -0.005 & \pm 0.007 & -0.00 & \pm 0.008 & 0.008 & \pm 0.10 & -0.00 & $5 \pm 0.003$ & -0.01 & \pm 0.006 \\
\hline & 800 & 8 & -0.00 & \pm 0.006 & & & -0.00 & $3 \pm 0.005$ & & & & & 0.017 & \pm 0.008 \\
\hline & 1200 & 6 & 0.010 & \pm 0.007 & & & 0.00 & $3 \pm 0.005$ & & & & & -0.02 & \pm 0.020 \\
\hline
\end{tabular}

* Data presented as mean $\pm \mathrm{SE}$ in millimoles/liter.

$\ddagger$ Data for the resting state represent the mean of 2-4 observations at 5- to 10 -min intervals in each subject.

vate, $8 \%$; glycerol $4.5 \%$; indocyanine green, $3.4 \%$; oxygen saturation $0.9 \%(20-50 \%)$ and $0.4 \%(90-100 \%)$.

Determination of portal vein glucose levels. To establish the relationship between true hepatic glucose output and estimated splanchnic glucose production (calculated as the product of hepatic blood flow and arterial-hepatic venous $[\mathrm{A}-\mathrm{HV}]^{1}$ glucose differences), arterial-portal venous (APV) glucose differences were measured in five patients (28-46 yr of age) undergoing elective surgery for uncomplicated cholelithiasis. A brachial artery catheter was inserted percutaneously before surgery, and duplicate blood samples were simultaneously collected during the surgical procedure from the protal vein by direct puncture and from the arterial catheter. The A-PV glucose difference was $0.08 \pm 0.03$ mmoles/liter (mean $\pm \mathrm{SE}$ ), and the arterial concentration was $6.09 \pm 0.36 \mathrm{mmoles} /$ liter. This A-PV difference for glucose is slightly larger than that previously reported by Myers (30) for three patients with cirrhosis of the liver and portal hypertension. The finding indicates that the splanchnic glucose production measured on the basis of A-HV glucose differences slightly underestimates the true hepatic glucose production. Considering the magnitude of the A-HV glucose differences reported below and since the estimated contribution of arterial blood to the total liver blood flow is approximately $30 \%(31)$, this error may be calculated to be $5 \%$ or less in the resting state. No correction has been applied for this underestimation.

Standard statistical methods have been employed (32) in analyzing the data, using the paired $t$ test when applicable.

\section{RESULTS}

Heart rate, oxygen uptake, and estimated leg blood flow. Data for heart rate and oxygen uptake at rest and during exercise are given in Table I. Mild exercise at

${ }^{1}$ Abbreviations used in this paper: A-FV, arterial-femoral venous; $\mathrm{A}-\mathrm{HV}$, arterial-hepatic venous; $\mathrm{A}-\mathrm{PV}$, arterialportal venous; EHBF, estimated hepatic blood flow.
$400 \mathrm{~kg}-\mathrm{m} / \mathrm{min}$ increased basal oxygen uptake approximately 4-fold. Exercise at $800 \mathrm{~kg}-\mathrm{m} / \mathrm{min}$ caused a 6 - to 7 -fold rise in oxygen uptake, while the heaviest work load was associated with a 9- to 10 -fold increase. Both heart rate and oxygen uptake were found to increase slightly during the course of the 40 min exercise period, as has been reported previously (33). There was a marked rise in the arterial-femoral venous (A-FV) oxygen difference and thus a fall in FV oxygen saturation after $10 \mathrm{~min}$ of exercise. Between the 10th and 40th min of exercise a small further increase in A-FV oxygen difference was seen at all work loads. Estimated blood flow to the leg increased approximately 4-fold at 400 $\mathrm{kg}-\mathrm{m} / \mathrm{min}$ and 8 - to 12 -fold at the heavier work loads. The hematocrit increased slightly at the onset of exercise and then remained constant.

Arterial substrate concentration. Table II presents the arterial concentrations of glucose, lactate, pyruvate, glycerol, and free fatty acids at rest and during exercise. The arterial glucose concentration was not significantly changed during mild exercise at $400 \mathrm{~kg}-\mathrm{m} / \mathrm{min}$. However, work loads of 800 and $1200 \mathrm{~kg}-\mathrm{m} / \mathrm{min}$ elicited a gradual rise in the glucose concentration which was most pronounced for the heaviest load (Fig. 1). Lactate, pyruvate, and glycerol concentrations all increased with exercise, the last demonstrating a progressive rise throughout the exercise period. Free fatty acid concentrations fell $15-30 \%$ after $10 \mathrm{~min}$ of exercise $(P<0.01)$. This initial fall was followed by a gradual rise during the remainder of the exercise period to levels which at $40 \mathrm{~min}$ exceeded the resting concentration $(P<0.01)$.

Arterial plasma insulin levels were determined in 10 subjects as shown in Fig. 2. The mean plasma level of 
TABLE IV

Arterial-Hepatic Venous Differences (A-HV) for Glucose, Lactate, Pyruvate, Glycerol, and Oxygen and Hepatic Vein Oxygen Saturation at Rest and during Exercise at Different Work Loads*

\begin{tabular}{|c|c|c|c|c|c|c|c|c|c|c|c|c|}
\hline \multirow[b]{2}{*}{ A-HV } & \multirow{2}{*}{$\begin{array}{l}\text { Work } \\
\text { load }\end{array}$} & \multirow[b]{2}{*}{$\mathbf{n}$} & \multirow{2}{*}{\multicolumn{2}{|c|}{ Rest $\ddagger$}} & \multicolumn{8}{|c|}{ Exercise } \\
\hline & & & & & $5 \mathrm{~min}$ & 10 & $\min$ & 20 & $\min$ & $30 \mathrm{~min}$ & $40 n$ & $\min$ \\
\hline \multicolumn{13}{|c|}{$k g-m / \min$} \\
\hline \multirow{4}{*}{$\begin{array}{l}\text { Glucose, } \\
\text { mmoles/liter }\end{array}$} & & & & & & & & & & & & \\
\hline & 400 & 5 & -0.79 & \pm 0.06 & $-1.17 \pm 0.35$ & -1.00 & \pm 0.14 & -1.59 & \pm 0.31 & $-2.15 \pm 0.95$ & -2.38 & \pm 0.85 \\
\hline & 800 & 7 & -0.86 & \pm 0.12 & $-2.08 \pm 0.95$ & -1.97 & \pm 0.56 & -3.59 & \pm 1.01 & $-4.28 \pm 1.06$ & -4.80 & \pm 1.38 \\
\hline & 1200 & 4 & -0.67 & \pm 0.08 & $-1.46 \pm 0.58$ & -2.66 & \pm 0.62 & -3.99 & \pm 1.29 & $-6.58 \pm 1.32$ & -5.98 & \pm 0.78 \\
\hline \multirow[t]{3}{*}{$\begin{array}{l}\text { Lactate, } \\
\text { mmoles/liter }\end{array}$} & 400 & 5 & 0.18 & \pm 0.07 & $0.06 \pm 0.37$ & 0.35 & \pm 0.14 & 0.43 & \pm 0.13 & $0.36 \pm 0.18$ & 0.50 & \pm 0.20 \\
\hline & 800 & 7 & 0.22 & \pm 0.12 & $1.11 \pm 0.32$ & 0.86 & \pm 0.25 & 0.76 & \pm 0.23 & $0.65 \pm 0.18$ & 0.58 & \pm 0.19 \\
\hline & 1200 & 6 & 0.24 & \pm 0.07 & $2.01 \pm 0.45$ & 0.91 & \pm 0.21 & 0.79 & \pm 0.18 & $0.81 \pm 0.40$ & 0.52 & \pm 0.12 \\
\hline \multirow[t]{3}{*}{$\begin{array}{l}\text { Pyruvate, } \\
\text { mmoles/liter }\end{array}$} & 400 & 5 & -0.003 & \pm 0.013 & & 0.018 & \pm 0.012 & & & & 0.025 & \pm 0.011 \\
\hline & 800 & 7 & 0.019 & \pm 0.007 & & 0.051 & \pm 0.026 & & & & 0.064 & \pm 0.015 \\
\hline & 1200 & 6 & 0.020 & \pm 0.003 & & 0.029 & \pm 0.018 & & & & 0.054 & \pm 0.013 \\
\hline \multirow{4}{*}{$\begin{array}{l}\text { Glycerol, } \\
\text { mmoles/liter }\end{array}$} & & & & & & & & & & & & \\
\hline & 400 & 3 & 0.035 & \pm 0.006 & & 0.111 & \pm 0.022 & 0.138 & \pm 0.036 & & 0.235 & \pm 0.040 \\
\hline & 800 & 3 & 0.051 & \pm 0.031 & & 0.088 & \pm 0.048 & 0.142 & \pm 0.077 & & 0.194 & \pm 0.105 \\
\hline & 1200 & 5 & 0.062 & \pm 0.006 & & 0.139 & \pm 0.026 & 0.209 & \pm 0.032 & & 0.357 & \pm 0.039 \\
\hline \multirow[t]{3}{*}{ Oxygen, $m l / l i l e r$} & 400 & 5 & 50.6 & \pm 3.2 & & 75.0 & \pm 6.4 & 91.1 & \pm 6.7 & & 90.5 & \pm 13.4 \\
\hline & 800 & 7 & 49.1 & \pm 6.6 & & 85.8 & \pm 8.6 & 97.3 & \pm 14.3 & & 120.9 & \pm 15.7 \\
\hline & 1200 & 6 & 47.8 & \pm 2.5 & & 112.4 & \pm 9.3 & 136.0 & \pm 8.2 & & 160.7 & \pm 4.4 \\
\hline \multicolumn{13}{|l|}{ HV oxygen } \\
\hline \multirow[t]{3}{*}{ saturation, $\%$} & 400 & 5 & 72.2 & \pm 2.0 & & 59.0 & \pm 3.5 & 49.8 & \pm 3.4 & & 50.3 & \pm 7.1 \\
\hline & 800 & 7 & 70.4 & \pm 1.9 & $\cdot$ & 54.3 & \pm 6.7 & 50.6 & \pm 7.7 & & 36.4 & \pm 8.2 \\
\hline & 1200 & 6 & 73.3 & \pm 1.3 & & 38.6 & \pm 3.8 & 24.4 & \pm 4.0 & & 12.0 & \pm 1.5 \\
\hline
\end{tabular}

* Data presented as mean $\pm \mathrm{SE}$ in millimoles/liter for glucose, lactate, pyruvate, and glycerol, in milliliters/liter for oxygen, and in per cent for HV oxygen saturation.

‡ Data for the resting state represent the mean of 2-4 observations at 5- to 10 -min intervals in each subject.

insulin was $7.0 \pm 0.8 \mu \mathrm{U} / \mathrm{ml}$ (mean $\pm \mathrm{SE}$ ) at rest. During exercise arterial insulin levels fell slightly to $5.6 \pm 0.8$ $\mu \mathrm{U} / \mathrm{ml}(P<0.01$, paired $t$ test $)$ at $10 \mathrm{~min}$ and to 5.0 $\pm 0.8 \mu \mathrm{U} / \mathrm{ml}$ at $40 \mathrm{~min}(P<0.05)$.

Leg metabolism. The influence of exercise on substrate exchange across the leg is shown in Table III. In the resting state there was significant net uptake of glucose and release of lactate across the leg. Exercise at 400 and $800 \mathrm{~kg}-\mathrm{m} / \mathrm{min}$ resulted in a progressive increase in the arterial-femoral venous (A-FV) difference for glucose during the entire work period (Fig. 1). With severe exercise $(1200 \mathrm{~kg}-\mathrm{m} / \mathrm{min})$ the A-FV difference for glucose increased markedly during the first $5 \mathrm{~min}$ and then stabilized, demonstrating only a moderate further rise during the last $15 \mathrm{~min}$ of the exercise period (Fig. 1). The values obtained at $1200 \mathrm{~kg}-\mathrm{m} / \mathrm{min}$ were significantly higher during the entire period of exercise than those obtained for either of the other work loads $(P<0.001)$.

The mean A-FV differences for lactate were negative both at rest and during exercise (Table IV). However, this value was significantly different from zero only in the resting state $(P<0.05)$. The pyruvate $\mathrm{A}-\mathrm{FV}$ differences did not differ significantly from zero at any time.

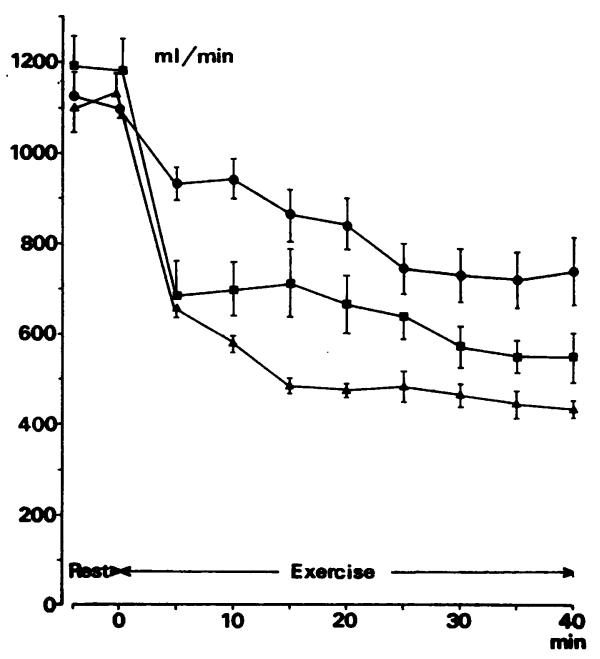

FIGURE 3 Estimated hepatic blood flow at rest and during exercise (mean $\pm \mathrm{SE}$ ) at work intensities of 400,800 , and $1200 \mathrm{~kg}-\mathrm{m} / \mathrm{min}$. Symbols as in Fig. 1. 
TABLE V

Splanchnic Glucose Production and Uptake of Lactate, Glycerol, and Oxygen at Rest and during Exercise at Different Work Loads*

\begin{tabular}{|c|c|c|c|c|c|c|c|c|c|c|c|c|}
\hline & \multirow{2}{*}{$\begin{array}{l}\text { Work } \\
\text { load }\end{array}$} & \multirow[b]{2}{*}{$\mathrm{n}$} & \multirow{2}{*}{\multicolumn{2}{|c|}{ Rest $\ddagger$}} & \multicolumn{8}{|c|}{ Exercise } \\
\hline & & & & & $5 \mathrm{~min}$ & \multicolumn{2}{|c|}{$10 \mathrm{~min}$} & \multicolumn{2}{|c|}{$20 \mathrm{~min}$} & $30 \mathrm{~min}$ & \multicolumn{2}{|c|}{$40 \mathrm{~min}$} \\
\hline \multicolumn{13}{|c|}{$\begin{array}{l}\qquad \begin{array}{c}k g-m / m i n \\
\text { Glucose production, }\end{array}\end{array}$} \\
\hline mmoles/min & 400 & 5 & 0.80 & \pm 0.06 & $1.21 \pm 0.38$ & 0.99 & \pm 0.19 & 1.48 & \pm 0.20 & $1.42 \pm 0.54$ & 1.64 & \pm 0.46 \\
\hline & 800 & 7 & 0.82 & \pm 0.10 & $0.90 \pm 0.24$ & 1.23 & \pm 0.31 & 2.07 & \pm 0.48 & $2.07 \pm 0.42$ & 2.23 & \pm 0.49 \\
\hline & 1200 & 4 & 0.81 & \pm 0.09 & $1.42 \pm 0.28$ & 1.96 & \pm 0.27 & 2.60 & \pm 0.32 & $3.56 \pm 0.50$ & 3.76 & \pm 0.66 \\
\hline \multirow[t]{3}{*}{$\begin{array}{l}\text { Lactate uptake, } \\
\text { mmoles } / \text { min }\end{array}$} & 400 & 5 & 0.19 & \pm 0.04 & $0.48 \pm 0.12$ & 0.32 & \pm 0.12 & 0.33 & \pm 0.09 & $0.34 \pm 0.19$ & 0.33 & \pm 0.06 \\
\hline & 800 & 7 & 0.28 & \pm 0.06 & $0.84 \pm 0.23$ & 0.57 & \pm 0.16 & 0.44 & \pm 0.11 & $0.33 \pm 0.06$ & 0.27 & \pm 0.07 \\
\hline & 1200 & 4 & 0.25 & \pm 0.06 & $1.32 \pm 0.33$ & 0.63 & \pm 0.12 & 0.44 & \pm 0.11 & $0.45 \pm 0.29$ & 0.24 & \pm 0.06 \\
\hline \multicolumn{12}{|l|}{ Glycerol uptake, } & \pm 0.012 \\
\hline & 800 & 3 & \multicolumn{2}{|c|}{$0.030 \pm 0.004$} & & \multicolumn{2}{|c|}{$0.037 \pm 0.007$} & \multicolumn{2}{|c|}{$0.045 \pm 0.009$} & & \multicolumn{2}{|c|}{$0.054 \pm 0.011$} \\
\hline & 1200 & 5 & \multicolumn{2}{|c|}{$0.038 \pm 0.004$} & & \multicolumn{2}{|c|}{$0.046 \pm 0.008$} & \multicolumn{2}{|c|}{$0.058 \pm 0.009$} & & \multicolumn{2}{|c|}{$0.091 \pm 0.013$} \\
\hline \multicolumn{13}{|c|}{ Splanchnic oxygen } \\
\hline uptake, $m l / m i$ & in 400 & 5 & 52.4 & \pm 3.9 & & 67.1 & \pm 4.5 & 76.6 & \pm 12.6 & & 62.0 & \pm 4.9 \\
\hline & 800 & 7 & 59.7 & \pm 3.8 & & 59.4 & \pm 6.3 & 59.0 & \pm 6.7 & & 61.0 & \pm 5.7 \\
\hline & 1200 & 4 & 51.9 & \pm 4.2 & & 63.1 & \pm 7.6 & 64.5 & \pm 4.9 & & 71.4 & \pm 7.0 \\
\hline
\end{tabular}

* Data presented as mean \pm SE.

$\ddagger$ Data for the resting state represent the mean of 2-4 observations at 5- to 10 -min intervals in each subject.

Splanchnic metabolism. Estimated hepatic blood flow (EHBF) decreased markedly during exercise (Fig. 3). The adaptation to a new level of hepatic blood flow occurred during the first $20-30 \mathrm{~min}$ of the exercise period. On the average a $30 \%$ reduction was seen after $40 \mathrm{~min}$ at $400 \mathrm{~kg}-\mathrm{m} / \mathrm{min}$. Corresponding values for 800 and 1200 $\mathrm{kg}-\mathrm{m} / \mathrm{min}$ were 55 and $62 \%$.

The arterial-hepatic venous (A-HV) glucose difference increased progressively with exercise at all work loads, the rise being most marked at the heaviest load (Table IV). After $40 \mathrm{~min}$ there were for the 400,800 ,

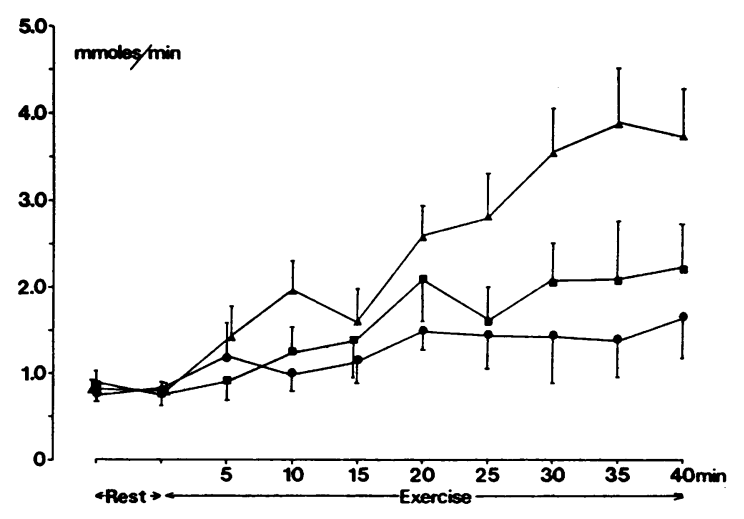

FIGURE 4 Estimated splanchnic glucose production at rest and during exercise (mean \pm SE) at work intensities of 400 , 800 , and $1200 \mathrm{~kg}-\mathrm{m} / \mathrm{min}$. Symbols as in Fig. 1. and $1200 \mathrm{~kg}-\mathrm{m} / \mathrm{min}$ groups approximately $2.5-, 6.5-$, and 13-fold increases respectively, in the A-HV glucose differences. Significant splanchnic uptakes were measured both at rest and during exercise for lactate, pyruvate, and glycerol (Table IV). Glycerol showed the highest splanchnic fractional extraction (expressed as [A-HV]/ A) of these substrates, with values of $91-100 \%$ at rest and $63-100 \%$ during exercise. Lactate fractional extraction was largest at the beginning of the exercise and then fell.

Splanchnic glucose production was calculated as the product of EHBF and the A-HV glucose difference ( Table V). A gradual increase with time was observed during exercise at all work loads, the rise in glucose production being most pronounced at the heaviest work load (Fig. 4). As compared with the resting state, splanchnic glucose output increased approximately 2-, 3-, and 5-fold

TABLE VI

Arterial-Renal Venous Differences for Glucose at Rest and during Exercise

\begin{tabular}{lcccrr}
\hline & \multicolumn{5}{c}{ Exercise, $800 \mathrm{~kg}-\mathrm{m} / \mathrm{min}$} \\
\cline { 3 - 6 } Subject & Rest & $10 \mathrm{~min}$ & $20 \mathrm{~min}$ & $30 \mathrm{~min}$ & $40 \mathrm{~min}$ \\
\hline Y. G. & 0.03 & 0.09 & -0.11 & -0.08 & 0.05 \\
M. F. & 0.05 & 0.10 & \pm 0 & 0.07 & -0.08 \\
\hline
\end{tabular}


after $40 \mathrm{~min}$ of exercise at work loads of 400,800 , and $1200 \mathrm{~kg}-\mathrm{m} / \mathrm{min}$, respectively. Estimated splanchnic glucose production after $40 \mathrm{~min}$ of exercise correlated directly with indices of relative work intensity such as heart rate $(r=0.75, P<0.001)$ and arterial lactate concentration $(r=0.83, P<0.001)$ and inversely with simultaneous hepatic venous oxygen saturation $(r=-$ $0.85, P<0.001)$. The reproducibility of the splanchnic glucose response to exercise is indicated by the data on subject C. G. who was studied on two occasions, on the second of which both a right and left hepatic vein were catheterized. As shown in Fig. 5 there was good agreement between the various estimates of splanchnic glucose output in this subject.

Splanchnic lactate uptake rose markedly within 5-10 min of initiation of exercise and subsequently demonstrated a continuous decline during the remainder of the exercise period (Table V). In contrast, glycerol uptake increased with time at all levels of work intensity mainly as a consequence of rising arterial glycerol concentrations. Exercise, particularly at the heavy work loads, was accompanied by a marked increase in fractional extraction of oxygen by the splanchnic bed as seen from the low levels of hepatic venous oxygen saturation and high A-HV oxygen differences (Table IV). Splanchnic oxygen uptake rose slightly during exercise (Table V), despite the pronounced fall in EHBF. For the entire group the mean increase from rest to $40 \mathrm{~min}$ of exercise was $15 \%(P<0.01)$.

Renal metabolism. To determine if the kidney is an important source of glucose production in exercise, a renal vein was catheterized in two subjects and arterialrenal venous glucose differences were determined (Table VI). No consistent uptake or production of glucose was found during exercise.

\section{DISCUSSION}

The current findings demonstrate the presence of significant extraction of glucose by leg tissue both at rest and during light as well as strenuous exercise. The femoral venous blood derives at rest from both muscle and subcutaneous tissue. Human subcutaneous tissue is known to utilize glucose (34), and its glucose uptake no doubt contributes to the A-FV difference seen at rest. However, the fraction of blood from subcutaneous tissue in the femoral venous drainage is likely to become successively smaller as the work load and component of muscle blood flow increase during exercise (35). Considering the large leg muscle mass and the high oxygen extraction ratio observed, it is likely that the A-FV differences for glucose measured during exercise are primarily representative of leg muscle metabolism.

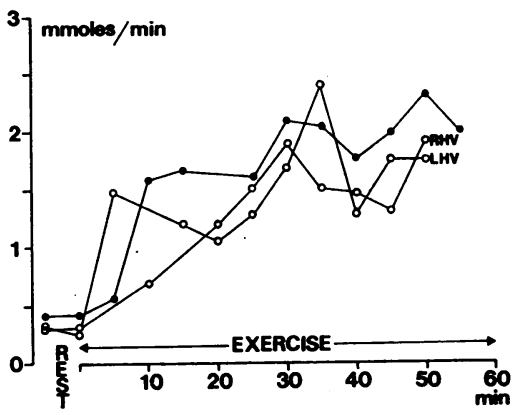

FIGURE 5 Splanchnic glucose production at rest and during exercise at $1200 \mathrm{~kg}-\mathrm{m} / \mathrm{min}$ in subject C. G. on one occasion (filled circles) and 3 months later (open circles), when glucose production was estimated from measurements on blood from both a right (RHV) and a left (LHV) sided hepatic vein.

At all levels of work intensity the A-FV glucose differences as well as leg blood flow increased, indicating that exercise resulted in a marked augmentation of net glucose uptake by the leg. The magnitude of this augmentation may be estimated from the product of leg blood flow (Table I) and the A-FV differences for glucose (Table III). By this calculation, glucose uptake by the leg increased 7 -fold above resting levels during light exercise $(400 \mathrm{~kg}-\mathrm{m} / \mathrm{min})$ and rose 10 - and 20 -fold at work intensities of 800 and $1200 \mathrm{~kg}-\mathrm{m} / \mathrm{min}$, respectively (Fig. 6).

Data for the estimated contribution of blood glucose to total oxidative metabolism of the leg are given in Table VII. Total oxidative metabolism has been determined from the A-FV oxygen difference; carbohydrate oxidation was estimated on the basis of the ventilatory respiratory quotient (Table I). The FV-A differences for lactate have been subtracted from the glucose A-FV differences so as to exclude that proportion of glucose

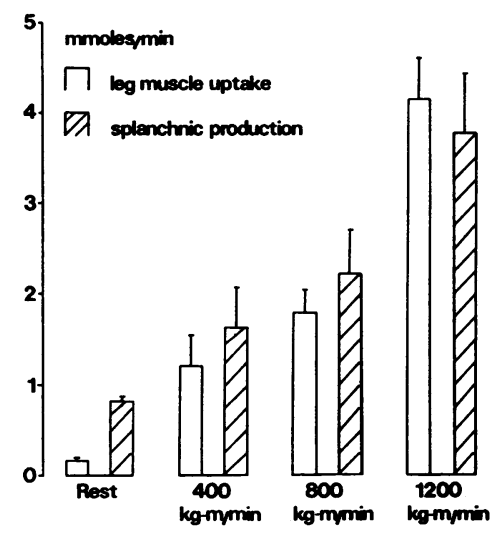

FIgURE 6 Comparison of estimated glucose uptake by the legs and splanchnic glucose production in subjects at rest and after $40 \mathrm{~min}$ of exercise at various work intensities (mean $\pm \mathrm{SE}$ ). 
TABLE VII

Estimated Contribution of Blood Glucose to Total Oxidation and to Total Carbohydrate Oxidation by the Leg at Rest and during Exercise at Different Loads

\begin{tabular}{|c|c|c|c|c|c|c|c|}
\hline & \multirow[b]{3}{*}{ Rest } & \multicolumn{6}{|c|}{ Exerçise } \\
\hline & & \multicolumn{2}{|c|}{$400 \mathrm{~kg}-\mathrm{m} / \mathrm{min}$} & \multicolumn{2}{|c|}{$800 \mathrm{~kg}-\mathrm{m} / \mathrm{min}$} & \multicolumn{2}{|c|}{$1200 \mathrm{~kg}-\mathrm{m} / \mathrm{min}$} \\
\hline & & $10 \mathrm{~min}$ & $40 \mathrm{~min}$ & $10 \mathrm{~min}$ & $40 \mathrm{~min}$ & $10 \mathrm{~min}$ & $40 \mathrm{~min}$ \\
\hline \multicolumn{8}{|l|}{ Substrate exchange } \\
\hline $\mathrm{A}-\mathrm{FV}$ Glucose, mmoles/liter & 0.18 & 0.21 & 0.36 & 0.22 & 0.40 & 0.34 & 0.49 \\
\hline FV-A $\mathrm{A}_{\text {Lactate, }}$ mmoles/liter & 0.14 & 0.11 & 0.09 & 0.23 & 0.04 & 0.03 & 0.12 \\
\hline $\mathrm{G}-\mathrm{L},{ }^{*}$ mmoles/liter & 0.66 & 0.93 & 1.89 & 0.63 & 2.28 & 1.95 & 2.58 \\
\hline \multicolumn{8}{|l|}{$\mathrm{O}_{2}$ uptake } \\
\hline $\mathrm{A}-\mathrm{FV}_{\mathrm{O}_{2}}$, mmoles/liter & 2.98 & 6.50 & 6.69 & 7.92 & 7.89 & 6.63 & 6.97 \\
\hline$\left(\mathrm{A}-\mathrm{FV}_{\mathrm{O}_{2}}\right)_{\mathrm{CHO}}, \ddagger$ mmoles/liter & 0.54 & 1.84 & 2.12 & 3.87 & 3.05 & 3.69 & 3.16 \\
\hline \multicolumn{8}{|c|}{ Blood glucose contribution to $\mathrm{O}_{2}$ uptake } \\
\hline$(\mathrm{G}-\mathrm{L}) / \mathrm{O}_{2}, \S \%$ & 22 & 14 & 28 & 8 & 29 & 29 & 37 \\
\hline$(\mathrm{G}-\mathrm{L}) / \mathrm{O}_{{ }^{2} \mathrm{CHO}}, " \%$ & $122 \uparrow$ & 51 & 89 & 16 & 75 & 53 & 82 \\
\hline
\end{tabular}

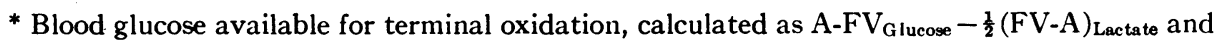
expressed as oxygen equivalents in millimoles/liter.

$\ddagger$ Oxygen uptake used for carbohydrate oxidation as estimated from RQ (Table II), expressed in millimoles/liter.

$\S$ The fraction of total oxygen uptake by the leg accounted for by oxidation of glucose extracted from the blood, expressed as per cent.

11 The fraction of the leg oxygen uptake used for carbohydrate oxidation accounted for by oxidation of glucose extracted from the blood, expressed as per cent.

I This value suggests that a portion of the glucose uptake in the resting state is stored in the form of glycogen and/or triglyceride, rather than oxidized or released as lactate.

uptake not available for terminal oxidation. This results in a slight overestimation of glucose available for oxidative metabolism, inasmuch as evidence is presented elsewhere that the carbon skeleton of glucose appears as alanine as well as lactate (14). However, since lactate release accounts for $5-12 \%$ of glucose uptake during prolonged exercise (Table VII) and "glucose-derived alanine" is estimated to be formed at approximately one-half the rate of lactate (36), this overestimation of oxidizable glucose is quite small.

During exercise, the data indicate that blood glucose oxidation covers an increasing fraction of both total and carbohydrate oxidation of the leg muscles at all levels of work intensity (Table VII), thereby substituting in part for the gradually diminishing endogenous muscle stores of carbohydrate $(13,37)$. While muscle glycogen is likely to be the dominating carbohydrate substrate during the initial phase of exercise, the utilization of blood glucose rises steadily with time. At 40 min of exercise blood glucose can-if completely oxidized-sustain as much as $75-90 \%$ of the carbohydrate metabolism and $28-37 \%$ of the total oxidative metabolism (Table VII). It should be emphasized that changes in blood flow need not be considered in these estimates of the relative contribution of glucose to oxidative metabolism since flow is the same for each substrate. On the other hand, due to the changing pattern of blood glucose and muscle glycogen utilization, values obtained at isolated points in time after the onset of exercise provide only a limited part of the whole picture and may not be representative of the entire scope of substrate utilization. Nevertheless, it can be concluded that during exercise with the large muscle groups of the leg, as in the case of rhythmic work with the forearm flexors $(8,38)$, blood glucose is a quantitatively important substrate for muscle oxidation.

With respect to the mechanism of the rise in glucose uptake, it is particularly noteworthy that a significant decrease in plasma insulin concentration was observed in association with exercise. In agreement with previous reports (39), the magnitude of this diminuation in insulin levels was quite small. However, the bidirectional response of circulating glucose and insulin, particularly with severe exercise (40), suggests that insulin secretion was in fact inhibited during physical work, perhaps as a consequence of increased release 
TABLE VIII

Balance of Glucose and Gluconeogenic Substrates across the Splanchnic Bed at Rest and during Exercise at Different Work Loads

\begin{tabular}{|c|c|c|c|c|c|c|c|}
\hline & \multirow[b]{3}{*}{ Rest } & \multicolumn{4}{|c|}{ Exercise } & & \\
\hline & & \multicolumn{2}{|c|}{$400 \mathrm{~kg}-\mathrm{m} / \mathrm{min}$} & \multicolumn{2}{|c|}{$800 \mathrm{~kg}-\mathrm{m} / \mathrm{min}$} & \multicolumn{2}{|c|}{$1200 \mathrm{~kg}-\mathrm{m} / \mathrm{min}$} \\
\hline & & $10 \mathrm{~min}$ & $40 \mathrm{~min}$ & $10 \mathrm{~min}$ & $40 \mathrm{~min}$ & $10 \mathrm{~min}$ & $40 \mathrm{~min}$ \\
\hline Glucose production, mmoles/min & 0.81 & 0.99 & 1.64 & 1.23 & 2.23 & 1.96 & 3.76 \\
\hline \multicolumn{8}{|c|}{ Glucose-precursor uptake, ${ }^{*}$ mmoles $/$ min } \\
\hline Lactate & 0.120 & 0.160 & 0.165 & 0.285 & 0.135 & 0.315 & 0.120 \\
\hline Pyruvate & 0.008 & 0.009 & 0.010 & 0.018 & 0.018 & 0.009 & 0.012 \\
\hline Glycerol & 0.016 & 0.026 & 0.032 & 0.014 & 0.027 & 0.023 & 0.046 \\
\hline Glycogenic amino acids + & 0.053 & 0.047 & 0.063 & 0.042 & 0.056 & 0.038 & 0.043 \\
\hline Total precursor uptake, $\S$ mmoles $/$ min & 0.205 & 0.242 & 0.270 & 0.359 & 0.236 & 0.385 & 0.221 \\
\hline $\begin{array}{l}\text { Glucose production derivable from } \\
\text { precursor substrate, } \%\end{array}$ & 25.3 & 24.4 & 16.4 & 29.2 & 10.6 & 19.6 & 5.9 \\
\hline
\end{tabular}

* Expressed as glucose equivalents in millimoles/min.

‡ Sum of splanchnic uptake of alanine, glycine, serine, threonine, tyrosine, and phenylalanine; the data are based on the report of Felig and Wahren (14).

$\S$ Sum of uptakes of lactate, pyruvate, glycerol, and glycogenic amino acids, expressed as glucose equivalents in millimoles/min.

of norepinephrine $(41,42)$. It has been postulated that exercise-induced hypoinsulinemia serves to limit blood glucose uptake by muscle, thereby increasing its availability to the brain (40). However the current data provide direct evidence that glucose uptake by muscle is in fact stimulated in exercise despite a reduction in insulin levels. Thus our findings in intact normal man support the view based on in vitro evidence (43) and on studies in insulin-dependent diabetic subjects (44), that increased muscle glucose uptake during exercise does not depend on the ability to secrete increased quantities of insulin.

In accordance with previous studies $(12,13,45)$ splanchnic glucose output increased significantly at all levels of exercise. The importance of hepatic glucose production in the maintenance of blood glucose homeostasis during physical work and as a source of substrate for exercising muscle is underscored by the close agreement between estimated rates of glucose uptake by leg muscle and splanchnic glucose release (Fig. 6). In the resting condition splanchnic glucose output is far in excess of leg uptake inasmuch as the brain is the prime site of glucose utilization in the basal state (2). However, with increasing physical activity the relative contribution of cerebral glucose utilization to total uptake of blood glucose diminishes so that increasingly close correspondence is observed between splanchnic and leg glucose exchange (Fig. 6). In addition to the liver, the kidney has the capacity to synthetize significant amounts of glucose, particularly in the prolonged fasted state
(46). However direct measurements in this study in two subjects showed no detectable renal glucose production. Since no organ except the kidney and the liver is capable of significant gluconeogenesis and since muscle glycogenolysis, in the absence of glucose-6-phosphatase in muscle, is unlikely to contribute significantly to the blood glucose level, it is concluded that hepatic glucose mobilization is the dominant and quite likely the sole source of the increased amounts of glucose utilized during exercise.

The splanchnic balance of the gluconeogenic substrates lactate, pyruvate, glycerol, and glyconeogenic amino acids is shown in Table VIII. The sum of these compounds divided by two gives an estimate of the theoretically possible rate of gluconeogenesis assuming maximum conversion efficiency. The data indicate that at rest, approximately $25 \%$ of the glucose output may have been derived from the measured precursor substrates and approximately $16 \%$ from lactate and pyruvate, which is in reasonable agreement with results obtained using other techniques (47-49) and our own previously published data (49). During exercise total substrate extraction initially increased primarily as a result of increased uptake of lactate. As the exercise proceeded, total glucose production increased further although total precursor uptake remained unchanged $(400 \mathrm{~kg}-\mathrm{m} / \mathrm{min}$ group) or decreased $(800$ and $1200 \mathrm{~kg}$ $\mathrm{m} / \mathrm{min}$ groups) as a result of diminished lactate uptake. Accordingly, the possible contribution from gluconeogenesis fell, so as to account for only $6-11 \%$ of 
total glucose output after 40 of exercise at the heavier work loads (Table VIII). It is thus apparent that during exercise, particularly at heavy work loads, the major part of the splanchnic glucose production is derived from hepatic glycogenolysis. Approximate calculations of the area under the splanchnic glucose production curves show that an average of 100 mmoles or $18 \mathrm{~g}$ of glucose was formed during a $40 \mathrm{~min}$ exercise period at $1200 \mathrm{~kg}-\mathrm{m} / \mathrm{min}$, which appears quite reasonable in view of recent reports of a liver glycogen content of approximately $50 \mathrm{~g} / \mathrm{kg}$ for postabsorptive man (50).

As to the factors responsible for increased glycogenolysis in exercise, the fall in plasma insulin levels may be of some significance. The importance of small changes in insulin secretion in modulating splanchnic glucose balance has recently been demonstrated in intact man during the infusion of glucose (49). Furthermore, peripheral insulin levels may not fully reflect the extent of alteration in portal venous insulin concentration (51). Alternatively, increased adrenergic activity with physical exertion may contribute to stimulation of glycogenolysis. However, plasma epinephrine levels fail to increase significantly with exercise (52). Although the concentration of norepinephrine does rise, it is a far less potent stimulus of hepatic glucose release (53). Nevertheless, augmented activity of the sympathetic innervation of the liver remains a possibility. Hepatic hypoxia has also been proposed as a glycogenolytic stimulus in exhaustive exercise (45). However, this is unlikely to be of importance in the current study, in view of the observed increase in splanchnic oxygen consumption (Table V). Finally, the possibility of altered glucagon secretion must be considered and cannot be excluded on the basis of currently available data.

\section{ACKNOWLEDGMENTS}

We thank Rosa Koff, Ann-Mari Neuschütz, Soile Reilo, and Donna Murray, for their expert technical assistance.

This work was supported by a grant from the Swedish Medical Research Council (B71-19-X-3108) and by U. S. Public Health Service Grant AM-13526.

\section{REFERENCES}

1. Wahren, J., G. Ahlborg, P. Felig, and L. Jorfeldt. 1971. Glucose metabolism during exercise in man. Advan. Exp. Med. Biol. 11 : 189.

2. Cahill, G. F., Jr., and O. E. Owen. 1968. Some observations on carbohydrate metabolism in man. In Carbohydrate Metabolism and its Disorders. F. Dickens, P. J. Randle, and W. J. Whelan, editors. Academic Press, Inc., New York. 1: 497.

3. Andres, R., G. Cader, and K. L. Zierler. 1956. The quantitatively minor role of carbohydrate in oxidative metabolism by skeletal muscle in intact man in the basal state. Measurements of oxygen and glucose uptake and carbon dioxide and lactate production in the forearm. J. Clin. Invest. 35: 671.

4. Rabinowitz, D., and K. L. Zierler. 1962. Role of free fatty acids in forearm metabolism in man, quantitated by use of insulin. J. Clin. Invest. 41: 2191.

5. Reichard, G. A., B. Issekutz, Jr., P. Kimbel, R. C. Putnam, N. J. Hochella, and S. Weinhouse. 1961. Blood glucose metabolism in man during muscular work. $J$. Appl. Physiol. 16: 1001.

6. Havel, R. J., B. Pernow, and N. L. Jones. 1967. Uptake and release of free fatty acids and other metabolites in the legs of exercising men. J. Appl. Physiol. 23: 90.

7. Keul, J., E. Doll, and D. Keppler. 1967. The substrate supply of the human skeletal muscle at rest, during and after work. Experientia (Basel). 23: 974.

8. Jorfeldt, L., and J. Wahren. 1970. Human forearm muscle metabolism during exercise. V. Quantitative aspects of glucose uptake and lactate production during prolonged exercise. Scand. J. Clin. Lab. Invest. 26: 73.

9. Bergström, J., and E. Hultman. 1966. The effect of exercise on muscle glycogen and electrolytes in normals. Scand. J. Clin. Lab. Invest. 18: 16.

10. Baker, P. G., and R. F. Mottram. 1968. The metabolism of exercising human muscle. J. Physiol. (London). 194: 64P.

11. Klassen, G. A., G. M. Andrew, and M. R. Becklake. 1970. Effect of training on total and regional blood flow and metabolism in paddlers. J. Appl. Physiol. 28: 397.

12. Rowell, L. B., E. J. Masoro, and M. J. Spencer. 1965. Splanchnic metabolism in exercising man. J. Appl. Physiol. 20: 1032.

13. Bergström, J., and E. Hultman. 1967. A study of the glycogen metabolism during exercise in man. Scand. J. Clin. Lab. Invest. 19: 218

14. Felig, P., and J. Wahren. 1971. Amino acid metabolism in exercising man. J. Clin. Invest. 50: 2703.

15. Bradley, S. E. 1948. Measurements of hepatic blool flow. Methods Med. Res. 1: 199.

16. Rowell, L. B., K. K. Kraning II, T. O. Evans, J. W. Kennedy, J. R. Blackmon, and F. Kusumi. 1966. Splanchnic removal of lactate and pyruvate during prolonged exercise in man. J. Appl. Physiol. 21: 1773.

17. Bradley, S. E. 1946. Liver function as studied by hepatic vein catheterization. In Transactions of the Fifth Conference on Liver Injury. Josiah Macy, Jr. Foundation, New York. 38.

18. Jorfeldt, L., and J. Wahren. 1971. Leg blood flow during exercise. Clin. Sci. (London). In press.

19. Hugett, A. S. G., and D. A. Nixon. 1957. Use of glucose oxidase, peroxidase, and o-dianisidine in determination of blood and urinary glucose. Lancet. 2: 368.

20. Hjelm, M., and C. H. de Verdier. 1963. A methodological study of the enzymatic determination of glucose in blood. Scand. J. Clin. Lab. Invest. 15: 415.

21. Wahren, J. 1966. Quantitative aspects of blood flow and oxygen uptake in the human forearm during rhythmic exercise. Acta Physiol. Scand. 67(Suppl.) : 269.

22. Segal, S., A. E. Blair, and J. B. Wyngaarden. 1956. An enzymatic spectrophotometric method for the determination of pyruvic acid in blood. J. Lab. Clin. Med. 48: 137. 
23. Bücher, T., R. Czok, W. Lamprecht, and E. Latzko. 1962. Pyruvat. In Methoden der enzymatischen Analyse. H. U. Bergmeyer, editor. Verlag-Chemie, Weinheim. 253.

24. Wieland, O. 1962. Glycerin. In Methoden der enzymatischen Analyse. H. U. Bergmeyer, editor. VerlagChemie, Weinheim. 211.

25. Hagenfeldt, L. 1966. A gas chromatographic method for the determination of individual free fatty acids in plasma. Clin. Chim. Acta. 13: 266.

26. Rosselin, G., R. Assan, R. S. Yalow, and S. Berson. 1966. Separation of antibody-bound and unbound peptide hormone labelled with iodine- 131 by talcum powder and precipitated silica. Nature (London). 212: 355.

27. Drabkin, D. L. 1950. Measurement of $\mathrm{O}_{2}$-saturation of blood by direct spectrophotometric determination. Methods Med. Res. 2: 159.

28. Drabkin, D. L., and J. H. Austin. 1935. Spectrophotometric studies. II. Preparations from washed blood cells: nitric oxide hemoglobin and sulfhemoglobin. $J$. Biol. Chem. 112: 51.

29. Garby, L., and J. C. Vuille. 1961. The amount of trapped plasma in a high speed microcapillary hematocrit centrifuge. Scand. J. Clin. Lab. Invest. 13: 642.

30. Myers, J. D. 1950. Net splanchnic glucose production in normal man and in various disease states. J. Clin. Invest. $29: 1421$.

31. Chiandussi, L., F. Greco, G. Sardi, A. Vaccarino, C. M. Ferraris, and B. Curti. 1968. Estimation of hepatic arterial and portal venous blood flow by direct catheterization of the vena porta through the umbilical cord in man. Preliminary results. Acta Hepato-Splenol. 15: 166.

32. Snedecor, G. W. 1956. Statistical Methods Applied to Experiments in Agriculture and Biology. Iowa State University Press. Ames. 5th edition.

33. Ekelund, L. G. 1967. Circulatory and respiratory adaptation during prolonged exercise. Acta Physiol. Scand. 70(Suppl. 212): 1 .

34. Pozefsky, T., P. Felig, J. D. Tobin, J. S. Soeldner, and G. F. Cahill, Jr. 1969. Amino acid balance across tissues of the forearm in postabsorptive man. Effects of insulin at two dose levels. J. Clin. Invest. 48: 2273.

35. Pernow, B., J. Wahren, and S. Zetterquist. 1965. Studies on the peripheral circulation and metabolism in man. IV. Oxygen utilization and lactate formation in the legs of healthy young men during strenuous exercise. Acta Physiol. Scand. 64: 289.

36. Felig, P., and J. Wahren. 1971. Interrelationship between amino acid and carbohydrate metabolism during exercise: the glucose alanine-cycle. Advan. Exp. Med. Biol. 11 : 205.

37. Hermansen, L., E. Hultman, and B. Saltin. 1967. Muscle glycogen during prolonged severe exercise. Acta Physiol. Scand. 71: 129.
38. Wahren, J. 1970. Human forearm muscle metabolism during exercise. IV. Glucose uptake at different work intensities. Scand. J. Clin. Lab. Invest. 25: 129.

39. Hunter, W. M., and M. Y. Sukkar. 1968. Changes in plasma insulin levels during muscular exercise. $J$. Physiol. (London). 196: 110P.

40. Pruett, E. D. R. 1970. Plasma insulin concentrations during prolonged work at near maximal oxygen uptake. J. Appl. Physiol. 29: 155.

41. Häggendal, J., L. H. Hartley, and B. Saltin. 1970. Arterial noradrenaline concentration during exercise in relation to the relative work levels. Scand. J. Clin. Lab. Invest. 26: 337.

42. Porte, D., and R. H. Williams. 1966. Inhibition of insulin release by norepinephrine in man. Science (Washington). $152: 1248$.

43. Goldstein, M. S., V. Mullic, B. Huddlestun, and R. Levine. 1953. Action of muscular work on transfer of sugars across cell barriers: comparison with action of insulin. Amer. J. Physiol. 173: 212.

44. Sanders, G. A., C. E. Levinson, W. H. Abermann, and N. Freinkel. 1964. Effect of exercise on the peripheral utilization of glucose in man. N. Engl. J. Med. 271: 220.

45. Rowell, L. B., G. L. Brengelmann, J. R. Blackmon, R. D. Twiss, and F. Kusumi. 1968. Splanchnic blood flow and metabolism in heat-stressed man. J. Appl. Physiol. 24: 475 .

46. Owen, O. E., P. Felig, A. P. Morgan, J. Wahren, and G. F. Cahill, Jr. 1969. Liver and kidney metabolism during prolonged starvation. J. Clin. Invest. 48: 574.

47. Reichard, G. A., Jr., N. F. Moury, N. J. Hochella, A. L. Petterson, and S. Weinhouse. 1963. Quantitative estimation of the Cori cycle in the human. J. Biol. Chem. 238: 495.

48. Cahill, G. F., Jr., M. G. Herrera, A. P. Morgan, J. S. Soeldner, J. Steinke, P. L. Levy, G. A. Reichard, Jr., and D. M. Kipnis. 1966. Hormone-fuel interrelationships during fasting. J. Clin. Invest. 45: 1751.

49. Felig, P., and J. Wahren. 1971. Influence of endogenous insulin secretion on splanchnic glucose and amino acid metabolism in man. J. Clin. Invest. 50: 1702.

50. Hultman, E., and L. H. Nilsson. 1971. Liver glycogen in man. Effect of different diets and muscular exercise. Advan. Exp. Med. Biol. 11: 143.

51. Blackard, W. G., and N. C. Nelson. 19;0. Portal and peripheral vein immunoreactive insulin concentrations before and after glucose infusion. Diabetes. 19: 302.

52. Vendsalu, A. 1960. Studies on adrenaline and noradrenaline in human plasma. Acta Physiol. Scand. 49(Suppl. 173) : 1 .

53. Bearn, A. G., B. Billing, and S. Sherlock. 1951. The effect of adrenaline and noradrenaline on hepatic blood flow and splanchnic carbohydrate metabolism in man. J. Physiol. (London). 115: 430. 